\title{
UNIVERSITY OF WESTMINSTER
}

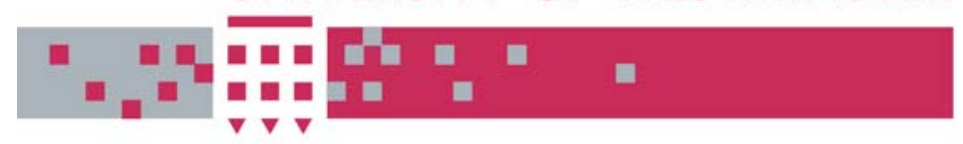

\section{WestminsterResearch}

http://www.wmin.ac.uk/westminsterresearch

\section{Widening participation in higher education: student quantitative skills and independent learning as impediments to progression.}

\section{Michael Pokorny ${ }^{1}$ \\ Helen Pokorny ${ }^{2}$}

${ }^{1}$ Department of Economics and Quantitative Methods, Westminster Business School, University of Westminster

${ }^{2}$ Centre for Academic Professional Development, London Metropolitan University

This is an electronic, author-formatted version of an article published in the Journal of Mathematical Education in Science and Technology, 36 (5). pp. 445-467, July 2005. The definitive version in the Journal of Mathematical Education in Science and Technology is available online at:

\section{http://dx.doi.org/10.1080/00207390500062621}

The WestminsterResearch online digital archive at the University of Westminster aims to make the research output of the University available to a wider audience. Copyright and Moral Rights remain with the authors and/or copyright owners.

Users are permitted to download and/or print one copy for non-commercial private study or research. Further distribution and any use of material from within this archive for profit-making enterprises or for commercial gain is strictly forbidden.

Whilst further distribution of specific materials from within this archive is forbidden, you may freely distribute the URL of WestminsterResearch.

(http://www.wmin.ac.uk/westminsterresearch).

In case of abuse or copyright appearing without permission e-mail wattsn@wmin.ac.uk. 
Widening participation in higher education: student quantitative skills and independent learning as impediments to progression

(Short title: Student quantitative skills and independent learning)

\author{
Michael Pokorny ${ }^{* \dagger}$ and Helen Pokorny ${ }^{\ddagger}$ \\ ${ }^{\dagger}$ Department of Economics and Quantitative Methods, University of Westminster, 35 \\ Marylebone Road, London NW1 5LS, United Kingdom \\ $\$$ Centre for Academic Professional Development, London Metropolitan University, 236-250 \\ Holloway Road, London N7 6PP, United Kingdom \\ E-mail: m.j.pokorny@westminster.ac.uk
}

* The author to whom correspondence should be addressed. 


\title{
Widening participation in higher education: student quantitative skills and independent learning as impediments to progression
}

\begin{abstract}
The UK government's widening participation strategy, and the concomitant development of a mass higher education system, has imposed a variety of pressures on higher education institutions. Not least of these is the changing nature of the student population, and the assumptions that can be made about its skills and knowledge base. It should not be surprising that this rapid expansion of the higher education system has resulted in declining student progression and retention rates. This paper takes a case study approach and attempts to identify the range of factors that might explain the variability of student performance on a first year undergraduate introductory statistics module. The paper concludes that there are no simple predictors of success or failure. However, there is evidence to suggest that any innovations in delivery need to take account of individual student development and that the presumption that students can rapidly become independent learners upon initial entry to higher education is an unrealistic one.
\end{abstract}

Keywords: quantitative methods; higher education; widening participation; independent learning. 


\section{Widening participation in higher education: student quantitative skills and independent learning as impediments to progression}

\section{Introduction}

The UK Government's policy objective of widening participation in higher education (HE) to $50 \%$ of all those under 30 years of age by 2010 is generally acknowledged to be an ambitious one. There have been a variety of concerns raised about the feasibility of such an objective. These include arguments that the UK HE system is grossly under-funded to absorb such a large expansion, that the secondary education system is ill-equipped to prepare such a large proportion of the student population for HE, and that, in any event, there is uncertainty as to whether there will be sufficient demand in the economy for such an increase in the supply of graduates.

This paper examines just one aspect of this debate. It focuses on the issue of the preparedness of students for $\mathrm{HE}$, with particular reference to the development of quantitative skills within a business education context, and the impact that this may have on student progression. This issue of mathematical/numerical literacy ${ }^{*}$ has been one that has stimulated considerable debate in policy and educational circles, ranging from the nature, quality and relevance of mathematical education at the primary and secondary levels, to employer needs with regard to the skills of graduates. An inquiry into post-14 mathematical education in the UK by Smith [1] concluded that there was a critical shortage of specialist mathematics

\footnotetext{
${ }^{*}$ We use the terms numeracy/mathematical literacy/quantitative skills interchangeably, and interpret them as being generic in the sense of describing a general facility for undertaking numerically-based educational programmes. While recognising that the specialist educational literature draws a distinction between these concepts, we do not consider these distinctions to be relevant within the context of the present study.
} 
teachers, that the current mathematics syllabus inadequately prepares students for the demands of higher education and fails to meet the needs of employers, and that insufficient emphasis is given to supporting teachers of mathematics via continuing professional development and other resources. The report emphasised that these failings are chronic, and cannot be overcome without significant intervention on the part of all relevant interest groups. A recently published report by Hoyles, et al, [2] emphasised the growing demand from employers for mathematically literate graduates, and the extent to which the mathematical literacy of its employees is seen as an important component of a firm's competitive strategy.

This paper examines student performance on a first-year undergraduate introductory business statistics module, with a particular emphasis on attempting to identify the determinants of the variability in performance. The approach taken is exploratory, in the sense that it is based on a case study of a single cohort of students in a single university. However, given that the university is an inner-city 'new' university - hitherto the type of university that has been the primary vehicle of the widening participation strategy - we would argue that the results of the study are at least suggestive of broader conclusions. The objectives of the paper are modest, in the sense that it attempts to identify the impediments to student progression, rather than to provide any detailed strategies to enhance student progression. This micro-level approach contrasts with macro-level approaches such as that of Smith and Naylor [3], which examined related issues (issues concerned with student withdrawal from HE study), but using data across the university sector as a whole. The analysis presented here can be interpreted as complementary to such studies in the sense that it attempts to explore a number of specific issues at a highly disaggregated level and hence could be used to inform conclusions drawn within these broader contexts. 
In his survey of the factors that impact upon student retention (in contrast to the closely related issue of student progression examined here), Longden [4] emphasised the complexity of the issues involved, in terms of both the range of relevant factors and the interactions amongst them, and the failure of public debate to recognise this complexity. As the HE system has evolved rapidly from an elite one to one of mass entry, the factors that impact upon both student retention and progression have presumably changed, and yet remain relatively poorly understood. The methodology adopted here is quantitative, and multivariate in particular, and represents an initial attempt to both identify and quantify the range of factors that impact upon student progression, albeit at the level of a single module within a single university. The approach therefore contrasts with the qualitative analyses found in the much of the literature, although the approach and analyses presented here will be placed within the context of this literature, and will be presented as being complementary to it.

The module that is the focus of this study is a compulsory first-year undergraduate module in quantitative methods (QM) and information technology (IT). In terms of broad content, the module reviews basic algebraic concepts, equations and graphs of linear and nonlinear functions, before moving on to the core material of the module which focuses on the basic techniques of statistical analysis in the form of graphical and statistical summary measures of sample data and an introduction to correlation and regression analysis, but stopping short of any coverage of inferential statistics. All material is delivered within the context of the use of a spreadsheet package, and introduces students to a range of databases, both in-house and web-based. The broad objective of the module is to develop confidence in students to carry out and interpret basic data analyses, thereby providing a basis for empirical and project-based work in the subsequent modules that they undertake on their various 
programmes of study. The module recognises that many students come to this area of work with negative perceptions, reflecting the negative experiences of their pre-entry mathematics education. The module therefore attempts to counter some of this negativity by reviewing and reinforcing some basic mathematical concepts in the early weeks of the teaching programme, before moving on to the subject matter proper.

The module is located within what was then the Business School of the University of North London (now London Metropolitan University), an inner city post-1992 university with an established commitment to widening participation. Historically this has resulted in a high proportion of mature entrants (50\% within the Business School, and $70 \%$ across the institution), many of whom have been recruited on the basis of pre-entry Access course qualifications. However changes to student funding and the withdrawal of the student grant have resulted in a significant decrease in this market across the institution, an effect that has been noted by Marks [5]. There has also been a broadening of the meaning of "widening participation' in recent years on a national policy basis (Macdonald and Stratta [6]). Particular emphasis has been placed on widening access for young people from lower socioeconomic groups. These changes have taken place within a context of the development of a mass HE system with an accompanying fall in the average unit of resource (see Longden [4], for a more detailed discussion of these issues).

This paper makes an initial attempt to identify any systematic influences on student performance, at the module level, that might derive from the diversity of the student body. The aim is not to simplify the complex individual process of learning but to attempt to explore the possible effects of the change in the widening participation strategy as it may be 
impacting at the level of student learning by considering the nature of these changes at the cohort level.

The paper is structured as follows. The next section presents a review of the relevant literature in this area. This is followed by a brief description of the module that provides the context for the analysis, together with a description of the nature of the student cohort. A multivariate analysis of student performance is then presented. The paper concludes with a discussion of the interpretations and conclusions that might be drawn from this analysis.

\section{Literature Review}

Given the increasing heterogeneity of the student population that a widening participation strategy must necessarily generate, issues relating to student performance must be viewed within a relatively broad context. The literature review presented here is an attempt to define this context, and in particular, covers four broad areas that are generally held to impact upon student performance - gender, age, teaching and learning experiences, and of more recent concern within the context of the UK HE system, the increasing financial pressures that are experienced by students as a result of changes in funding mechanisms.

\subsection{Gender}

The differential performance of boys and girls in mathematics has been well documented. Burton [7] notes that in the UK males are over-represented at both ends of the grading scale upon the completion of compulsory schooling. However, Dowling [8] reports that school studies fail to find evidence of boys outperforming girls - indeed the opposite is the case up until the sixteen plus public examination. Research into gender and performance in 
mathematics highlights the power of external representations on our view of ourselves. Walden and Walkerdine [9] point to the interpretations of differential performance at sixteen as significant. For girls, social stereotyping attributes an assumption of lack of confidence or anxiety about mathematics that in turn reinforces what is expected, and can lead to a caring practice by teachers of lessening pressure on girls and offering softer options, which again can result in poorer performance and increasing anxiety. On the other hand boys' poorer performance can be attributed to a lack of care that might actually be taken as an indicator of real ability (Dowling [8]). Familiarity with the use of computers is equally likely to be gendered. Gorard et al [10] note that 'the culture of ICT is generally young, white, middle class and male, the very attributes of the traditional learning base the Government (and many others) wish to move beyond.'

\subsection{Age}

Brown et al [11] state that 'Concern over the national standards of numeracy has a long history in England' and there could be particular issues for mature students who may have avoided contact with the subject since school. However, Richardson [12] assessed the approach to study of mature students and found that even when assessed shortly after admission their approaches to study are more effective than those of younger students. However, while there is a general acceptance that mature students adopt a 'deeper' approach to their learning, there is some uncertainty as to how this translates into performance. Dickson et al [13] refer to evidence that suggests that mature students outperform younger students in humanities subjects, but not in sciences. They quote other evidence suggesting some confusion with regard to the impact of age. These conclusions are consistent with a survey of research into mature student performance presented by McGivney [14]. Broadly, the relationship between age and academic performance would appear to be complex, with 
many studies being inconclusive. There is evidence to suggest that students aged 26 to 30 outperformed students under 21 , but that performance after age 30 declined with age. Hirst [15] examined the performance of mature students on an undergraduate mathematics programme. There was some evidence that mature students performed just as satisfactorily as traditional school-leavers (although there were issues concerning completion rates, with a lower completion rate in the over-35 group, and much a higher non-completion rate amongst mature males, findings that are consistent with those of Smith and Naylor [3]). However, all students on the programme, mature or otherwise, were required to have standard matriculation qualifications in mathematics, which contrasts with mature student entry into many non-science HE programmes.

On a more general level, both Bowl [16] and Tett [17] emphasise the specific needs and requirements of mature students entering $\mathrm{HE}$, the resource implications that this has, but the general insensitivity of the HE system to these issues, as it now rapidly evolves into one of mass participation.

\subsection{Teaching and learning experiences}

Archer et al [18] state that to be successful on a task:

Students need not only prior declarative knowledge, but also an awareness of necessary cognitive and self-regulatory strategies, and when and how to deploy them. They also need to feel confident that they can be successful and have the motivation to complete the task. It is also important, particularly if students' confidence is not strong, that they are in an environment that encourages perseverance and keeps anxiety to a manageable level. 
A number of studies have reported on the negative attitudes held by undergraduates in relation to learning mathematics (Tobias [19], Hembree [20]). Boaler et al [21] point out that in mathematics, even where this was not the case with other subjects, the predominant practice in schools since the mid 1960s has been ability grouping or streaming. This has resulted in some students being labelled as weak in this subject throughout much of their educational life. They also note that allocation to the lower sets or streams often reflects inequities on the basis of race, gender and class. Classroom observations of students in the lower sets also evidenced a range of poor teaching and learning experiences. Therefore, it is to be expected that many students entering HE from the lower socio-economic target groups will also enter with low levels of confidence and independence in this subject.

At the same time Breen and Lindsay [22] note that the growth in the student population in HE has reduced the time and attention available for individual student needs. This means that universities are forced to expect a significant level of independence from students in their learning. Students are likely to encounter large lectures and an increasing level of interaction with learning technologies, and this appears particularly to be the case in the less discursive disciplines such as science and mathematics. Wilcox [23] notes that '[independent] learning seems to promise a reasonable solution to the immediate and very real problem of providing high quality educational experiences with less demand on public resources.' Archer et al [18] refer to the self-regulatory aspects of independent learning, 'that 
is, students' awareness of themselves as learners and the strategies they select to complete their work.' They identified a link between academic performance and the use of appropriate self-regulatory strategies. In their study students irresolute in their use of strategies did not perform as well as others.

Montgomery [24] also notes that for many students 'their previous learning history has given them learned helplessness' which in an environment requiring independent learning skills leaves students with feelings of anger, fear, abandonment and anxiety. Grayson et al [25] also point to a number of studies that indicate that students who are having difficulties may be reluctant to ask academic staff for help. Boaler et al [21] note that one of the major implications of ability grouping practices in mathematics was to reduce the focus upon developing independence in learning and to require all students to work at the same pace, this being a major source of anxiety for those students who silently perceived themselves to be falling behind the rest of the group.

The increasing use of the large lecture within an expanded HE sector has been noted above. Gibbs et al [26] studied the effects of class size on performance. They point out that whilst class sizes have increased, student performance in terms of degree classification, has actually improved over the system as a whole, leaving politicians and some senior management to argue that the effects of large classes and resource problems can be overcome. Various explanations could be provided for this paradox including that standards have declined. Although their study was carried out at the secondary school level, Eide and Showalter [27] argue that while the level of teaching resources might have an insignificant impact on average student performance (their study investigated the relationship between 
teaching resources and performance in mathematics), there was strong evidence to suggest that increased resources had a positive impact at both the lower and upper ends of the ability scale. That is, both less and more able students benefited from increased resourcing, while such an effect was not apparent if the focus of attention was the performance of the average student. Other investigations into the effects of large classes on student performance have indicated poorer grade performance (Lindsay and Paton-Saltzberg [28]), and as one would expect, that large lectures generally produce fewer interactions and of lower cognitive quality (Mahler et al, [29]). Gibbs et al [26] confirmed the conclusions of Lindsay and PatonSaltzberg [28] that modules with larger enrolments have lower average marks. There are also perhaps greater implications for some subjects than others. Goldfinch [30] comments that 'in mathematics where material is very structured...not grasping one concept can render the whole of the rest of the lecture unintelligible.' Whilst various methods have been suggested by which the lecture might be designed in order to make students think and engage actively (Hubbard [31]), Isaacs [32] notes 'The idea seems to be that since we cannot make contact with individual students to work through their difficulties we should present as wide a variety of ways to encounter the subject as possible, in the hope that one will prove apt for each student's development.'

In her study of a similar quantitative methods module to that investigated here, in which she compared the effectiveness of teaching students consistently in small groups of about 20 as opposed to using the traditional large lecture/seminar method, Goldfinch [30] found that both staff and students preferred smaller classes, with their opportunities for greater individual interaction. Students cited 'getting to know staff better' and 'feeling free to stop the lecturer and ask questions' as the main benefits. Staff felt better able to adjust the pace to suit the students. In formal lectures staff found it difficult to find the right level and 
inevitably some students were bored, some were lost. She found the smaller classes gave significantly higher examination results (the examination tested the ability to use mathematical and statistical techniques, perform calculations and interpret results), but had no impact upon the coursework marks (which tested more qualitative and transferable skills such as questionnaire design, report writing, oral presentation and teamwork). (The skills and knowledge assessed on the module that is the focus of this study are similar to those assessed by examination in the Goldfinch [30] study - see Section 3 below.)

\subsection{Part-time paid employment}

Recent changes to student funding have resulted in growing financial hardship amongst fulltime HE students. At the time of the current study, all students were subject to means tested fees, up to a maximum of $£ 1,075$ per annum. The previous grants system had been replaced by a low interest loans system, whereby students living away from home could borrow up to $£ 5,000$ per annum ( $£ 3,000$ if living at home). Additional grants were available for students with children/dependents, of around $£ 2,500$ per annum. There was also a range of discretionary grants available to cover various categories of hardship, although such grants were generally modest, and typically about $£ 500$ per annum. It is not surprising, therefore, that it is now common for many students to secure part-time employment in order to supplement these modest income levels, and this is particularly the case for mature students who would not generally be able to call on parental support.

Ford et al [33] cite studies by Sorensen and Winn [34] and Paton-Saltzberg and Lindsay [35] that indicate the negative academic consequences of paid employment reduced time for study, missed lectures and seminars and missed coursework deadlines. Paton-Saltzberg and Lindsay [35] also noted that students who work in term time get marks 
that are demonstrably poorer as a result. In a more recent study, Johnston [36] provides evidence to suggest that working about 12 hours or more a week tends to impact negatively on performance, with lower levels of employment having a negligible impact. Christie et al [37] conclude that while, in general, students appear to cope reasonably well with indebtedness and part-time employment, there were clear differences between various categories of students. In particular, and not surprisingly, students with parental support coped markedly better than those without. Thus those students who for whatever reason could not depend on any or only very limited financial support from parents worked significantly longer hours and incurred higher levels of debt, with a resultant negative impact on their studies. While the sample upon which the study was based focused on students under 25, the implications for mature students were clear - considerable financial hardship, and at the margins, a disincentive to undertake HE. Unsurprisingly, Smith and Naylor [3] found that students from poorer backgrounds were more likely to drop out of university.

\section{The Module}

The module that is the focus of this study (QM101 - Quantitative Methods and Information Technology) is a compulsory core module for most students undertaking business-related programmes of study. The module had recently seen an increase in failure rates - typically about a third of the cohort failed at the first attempt, although this fell to about $20 \%$ once allowance was made for a second attempt at the assessment.

The factors influencing student performance are complex and reflect issues of individual student characteristics, abilities and circumstances, and module content and delivery. In order to gain some insights into these issues the performance of the 326 
predominantly full time students taking the module for the first time during the 2000/01 academic year was analysed across a range of variables such as age, entry qualifications and gender. Qualitative data was also collected from students via a questionnaire concerning their attitudes towards the content and delivery of the module, together with information on the amount of the time devoted to seminar and assessment preparation, and the extent of commitment to paid employment.

The module spanned twelve teaching weeks and was taken during the first semester of full-time study. As already indicated, it covered basic statistics (up to simple correlation and regression analysis, but stopping short of any inferential statistics), and the use of a spreadsheet package and databases. Students received 3 contact hours per week, consisting of one formal lecture hour, delivered to up to 150 students, and two one hour smaller group sessions. One of these hours was a supervised session in a computer studio covering the use of a spreadsheet package and databases. The second was a classroom-based seminar session in which a tutor took students through exercises that they were expected to have attempted prior to the session. In addition to detailed lecture notes, a comprehensive set of seminar exercises was issued to students on a week-by-week basis, which formed the focus for reinforcing the lecture material. The exercises became increasingly applied and computerbased over the course of the semester. Answers (but not worked solutions) to these exercises were also provided so that students could assess their own progress and development. The smaller group sessions were in classes of around 20. The module was assessed by a single and lengthy individual piece of coursework that required students to demonstrate their understanding of the statistical concepts covered through the use of a spreadsheet package. The coursework was largely open-ended in the sense that students were required to locate their own data sets and develop their own applications to demonstrate their understanding of 
the material covered. Students were strongly encouraged to use data sets that were related to their chosen programme of study.

Although the module made no assumptions about entry level mathematics it might be expected that students with higher levels of ability and confidence in this subject would have performed better in the module. Students were taken from a wide range of backgrounds. Where they have taken GCSE mathematics it was possible that they will have achieved only a grade D, the highest possible achievement for some entrants to the GCSE examination at 16 (Boaler et al, [21]), or a grade E. Others will have covered mathematics within Access courses, or as part of international qualifications, or if they are mature students, without formal qualifications, they may have taken the university aptitude test. The data regarding GCSE mathematics achievement was unavailable for this cohort. However analysis of the performance in the module of a subsequent cohort indicates that whilst students achieving an A or B grade in the GCSE mathematics qualification achieved higher grades in the module, there was no significant difference in the module grades achieved by students entering with a GCSE mathematics grade C, D or E.

\section{The Nature of the Student Cohort}

Table 1 provides an age and gender breakdown of the student cohort (the 2000/1 cohort), and also provides a comparison with the 1997/8 cohort. The proportion of females increased

\footnotetext{
* This information was unavailable in the sense that while students had to demonstrate that they had achieved a minimum threshold level in mathematics upon application to the University, the specific mathematical qualification achieved was not subsequently recorded on the individual computerised student records - the qualification recorded was the broad qualification that formed the basis for admission.
} 
from $58 \%$ in $1997 / 8$ to $65 \%$. However, it is the change in the age composition that is perhaps most marked. Thus the mature student intake (those aged 21 or over) had declined from $55 \%$ of the cohort in $1997 / 8$ to just $36 \%$ in $2000 / 1$. In the case of females, the 25 to 35 age group halved in proportionate terms, this also being the case for males in the 21 to 24 age group.

The breakdown by ethnic background ${ }^{*}$ is shown in Table 2, a breakdown that has remained relatively stable since 1997/8.

[Insert Table 1 about here]

[Insert Table 2 about here]

Table 3 provides a breakdown by qualifications on entry. ${ }^{\dagger}$ The major changes since 1997/8 have been the near doubling of the Vocational category (in proportionate terms), at

\footnotetext{
${ }^{*}$ The ethnic categorisation derives from students defining their own ethnicity upon enrolment.
}

\footnotetext{
${ }^{\dagger}$ In terms of the specific entry qualifications in Table 3, Matriculation Qualifications would be defined as standard entry qualifications for HE, and includes A-levels for England and Wales and their equivalent in Scotland and Ireland. This category also includes a range of equivalent overseas qualifications, such as the baccalaureate. The second category in Table 3 - Vocational Qualifications - are here specific to the UK, and include General National Vocational Qualifications/National Vocational Qualifications at Level 3

(GNVQ/NVQ). These qualifications are more vocational in their orientation than A-levels and their equivalent, but are still considered to be a valid qualification for entry to HE. This category also includes BTEC National
} 
the expense of the Access/Foundation, non-formally qualified mature students and the Other (Overseas) categories. The decline in the Access/Foundation and mature student categories mirrors the decline in the entry of mature students reflected in Table 1 above.

Five per cent of the entrants were part-time and four per cent had a disability of some form, proportions that are relatively unchanged over the past three years. Fourteen per cent of the cohort fell into the 'overseas' category in terms of tuition fees status.

[Insert Table 3 about here]

Additional quantitative and qualitative information was collected by means of a questionnaire, ${ }^{*}$ which was completed by $86 \%$ of the cohort. The questionnaire collected data on the number of seminars attended, the time spent on seminar preparation and the

Certificates/Diplomas (BTEC NC/ND), a more established vocational qualification at post-16 level. Access/Foundation Courses are designed for mature students, generally without formal qualifications, or standard-age students who have not obtained matriculation qualifications, and provide a general orientation for HE study. The 'None - Mature Student' category would cover those mature students who have considerable work experience at a level considered appropriate to allow for direct entry to HE. The 'Other (Overseas)' category covers a range of overseas qualifications that do not fit neatly into the other categories, but are considered appropriate for HE entry.

\footnotetext{
${ }^{*}$ The questionnaire was included with the coursework for the module, and students were requested to submit a completed questionnaire when they submitted their coursework. However, students were guaranteed anonymity in the sense that the questionnaire was removed from the coursework before the coursework was passed on for marking.
} 
completion of the assessment and, in the case of full-time students, the extent of paid employment undertaken. Attitudinal information was also collected relating to various elements of module delivery.

In terms of seminar attendance, while students attended an average of 9 seminars for IT and QM out of a possible 11, there were substantial numbers of students attending relatively few seminars $-10 \%$ attending six or fewer IT seminars and $12 \%$ attending six or fewer QM seminars (16\% and $18 \%$, respectively, for seven or fewer seminars). Seminar attendance has been a chronic problem on the module, with attendance dropping off markedly as the semester progresses. Consequently, the seminars missed tended to be in the second half of the module, which are those most relevant for the purposes of the assessment. A similar, but more extreme, pattern occurs in the case of lecture attendance.

An average of 3.1 hours per week was spent on preparing the seminar exercises, the distribution of hours being widely dispersed and skewed (standard deviation 2.9 hours, median 2.0 hours). The total number of hours spent on completing the assessment was similarly distributed with a mean of 41.1 hours (standard deviation 31.3 hours, median 35 hours).

In terms of attitudes to various elements of the module, broad satisfaction was expressed in relation to the challenging nature of the module, its usefulness, the improved understanding derived in relation to both the QM and IT components, and the usefulness of the teaching materials (in all cases dissatisfaction with regard to these elements was expressed by less than $10 \%$ of the respondents). However in the case of lecture delivery 27 
$\%$ expressed dissatisfaction, $16 \%$ were dissatisfied with the lecture content, and $15 \%$ were dissatisfied with the effectiveness and appropriateness of seminar work. Respondents were also given the opportunity to add any further comments to their questionnaires. This opportunity was taken up by $23 \%$ of the respondents, of whom $72 \%$ expressed essentially negative views. Most of these negative comments were focused on the demanding nature of the module in terms of both the subject matter and the requirements of the assessment. Some questioned the relevance of the subject matter to their chosen programme of study. Many questioned the role that lectures play on the module. As detailed lecture notes were issued to all students, many students felt that the process of presenting these lecture notes in a lecture format was redundant - it would have been preferable to have more seminar time.

In terms of the positive comments, most concerned the challenging nature of the module, the difficulties encountered in completing the coursework, but the satisfaction that was derived in coming to terms with the subject matter and the learning that took place in completing the assessment.

The final component of the questionnaire concerned the extent of paid employment undertaken. Table 4 presents summary statistics for the full-time students.

[Insert Table 4 about here]

It is clear from Table 4 that a substantial proportion of students undertook part-time work, and that the level of work undertaken was extensive. This is particularly the case for mature students - the difference in the average weekly hours of employment between mature 
and standard-age (under 21) students is statistically significant at the one per cent level. Indeed, these proportions are markedly higher than those reported by the National Audit Office [38], presumably reflecting considerable variations across different groups of students, and the nature of the student cohort that is the focus of this study. The National Audit Office report [38] recommends a maximum of 12 hours employment per week, which stands in stark contrast to the averages in Table 4.

\section{A Multivariate Analysis of Student Performance}

The analysis here will be concerned only with those students who attempted the module for the first time (that is, students repeating from previous years are excluded), and the analysis will focus on the grades achieved after a second attempt at the assessment has been allowed for - students are offered a reassessment opportunity during the summer period should they fail their first attempt at the assessment. ${ }^{*}$ The total sample so defined consists of 326 students.

The average grade achieved was $49.1 \%$ (the pass grade was $40 \%$ ), with a standard deviation of 14.6. Nineteen per cent of the cohort failed the assessment after allowing for the reassessment ( $33 \%$ failed at the first assessment opportunity).

\footnotetext{
* Repeat students were omitted from the analysis in order to focus upon the experience of those students taking the module for the first time. The grade recorded for each student is the best grade achieved at either the initial assessment point or the reassessment point.
} 
A regression analysis was carried out in order to identify some of the factors that might explain the variation in the assessment grades. In terms of the issues discussed in Section 2 above, three of these potential influences are relatively straightforward to quantify. Thus gender is represented as a simple binary variable ( 1 if female, 0 if male). Given that the literature on the impact of age on performance is broadly inconclusive, age was measured in a variety of ways in an attempt to identify age effects empirically. Thus age was measured as a simple continuous variable, but also as a series of binary variables ( 1 if 21 or over, 0 otherwise, 1 if 25 or over, 0 otherwise, and 1 if 30 or over, 0 otherwise). The square, cube and natural logarithm of age were also used to test for non-linear effects. A similar approach was taken with regard to the impact of paid employment on performance - a continuous variable was used, with non-linear variants, but binary variables were also used to test for the possibility of discrete effects (Johnston [36], National Audit Office [38]).

A more problematical area was quantifying previous mathematical backgrounds. As already indicated such information was unavailable, in the form, say, of GCSE grades. However, even if such information was available, it would cover only a proportion of the cohort, given the diversity of the student intake. As the module was designed to incorporate a review of basic mathematical concepts, the real issue is perhaps the level of motivation, confidence and commitment of students, which may not be reflected in achievement at age 16. The approach taken here follows Goldfinch [30], and uses the average grade achieved by the student across all modules during the first year, but excluding the grade achieved on QM101.* While clearly such a portmanteau variable can reflect such potential influences

\footnotetext{
* The correlation between this variable and the final grade achieved on the module is 0.47 , and thus while certainly statistically significant, is perhaps not as high as might have been expected, and in particular, not so high as to swamp all other influences.
} 
only imperfectly, its main role is as a control variable, allowing for a more rigorous evaluation of the other potential influences on student performance. In terms of other measures of previous educational achievement the variables used here are binary variable interpretations of the range of entry qualifications shown in Table 3 above.

Finally, a set of variables was constructed reflecting the extent of commitment to the learning and assessment requirements of the module. Thus the number of hours spent per week in preparing seminar work and the total number of hours spent completing the assessment were included as variables. ${ }^{*}$ The number of seminars attended was also included, distinguishing between attendance at the IT and QM seminars. Binary variables were also considered with regard to ethnicity and disability. ${ }^{\dagger}$

A two-stage regression process was undertaken. First, stepwise regressions were run (using the SPSS package), across the student cohort in total and sub-divided by age and gender. This first stage of the process was used to identify a broad set of explanatory variables, and in particular, a variable was selected as a potential explanatory variable if it

\footnotetext{
* It might be expected that students may have found it difficult to draw such a distinction between these two aspects of the study demands of the module. However the correlation between these two variables was just 0.16 , which would suggest that this was not the case.
}

\footnotetext{
$\dagger$ These factors were found to be not statistically significant in all subsequent statistical analyses, and therefore will not be discussed any further. In the case of ethnicity this is consistent with the relevant literature (not reported here) which suggests that any apparent differences in student performance by ethnicity can be explained in terms of social class and educational backgrounds.
} 
appeared as significant in any of these initial stepwise regressions. The second stage of the process was to use this common set of explanatory variables in the regressions presented in Tables 5 to 7 below.

Table 5 presents regressions across all the students in the sample (note that sample sizes depend on response rates to the questionnaire and response rates to individual questions on the questionnaire). Two equations are presented. Equation (1) presents the results of the stepwise procedure described above. Equation (2) adds to this equation the portmanteau variable discussed above, the average grade achieved on all other modules undertaken in the first year of study, $A V G R A D E$.

[Insert Table 5 about here]

From Equation (1) the statistically significant factors are the hours spent per week in seminar preparation $(S E M P R E P)$, the natural logarithm ${ }^{*}$ of the total hours spent in completing the assessment $(\ln (A S S P R E P))$, the extent of commitment to paid employment per week (WORK12 - this is a binary variable taking on the value 1 if a full-time student

\footnotetext{
${ }^{*}$ The logarithm of assessment hours was used as its statistical performance was superior to that of the simple level of assessment hours. This can be rationalised by arguing that the log attenuates the impact of those small numbers of students who undertook very large numbers of assessment hours - there were declining marginal returns to the hours spent on assessment preparation. A similar effect was in evidence with regard to age - the impact of age on performance also appeared to have a declining marginal impact.
} 
works more than 12 hours per week, 0 otherwise ${ }^{*}$ ), whether or not the student entered with BTEC NC/ND qualifications ( 1 if the student entered on the basis of BTEC NC/ND qualifications, 0 otherwise), gender (the positive coefficient implying that females outperform males), and a mix of age variables ( $\operatorname{Ln}(A G E)$ is the logarithm of age on entry, $A G E 21$ takes on the value 1 if student is 21 years or older, 0 otherwise, and $A G E 30$ is 1 if student is 30 or older, 0 otherwise). Thus the implied age effect is such that performance declines with age (the negative coefficient on $\operatorname{Ln}(A G E)$ ), but there are returns to maturity, in the sense that this decline sets in at a higher level from age 21 and age $30 .^{\dagger}$ Such an implied age effect may go some way to explaining the inconclusiveness in the literature with regard to the impact of age on student performance. That is, there is not a simple relationship between age and performance, with declining performance by age not necessarily being inconsistent with there being some benefits deriving from maturity. The remaining variables (the number of IT seminars attended over the semester (ITSEMINARS)), and whether or not the student had matriculation qualifications (MATRIC - takes on the value 1 if a student has a matriculation

\footnotetext{
* The impact of commitment to paid employment was evaluated in a variety of ways. Initially, the variable was used in its raw and continuous form, as the reported number of hours worked. In general, this variable worked satisfactorily in the sense that it exerted a negative and statistically significant impact on performance in most of the regressions. However, in the context of the literature suggesting the possibility of a discrete effect - that students can undertake some modest level of paid employment with no effect on performance - various dichotomised versions of the variable were also tested. In general these produced superior statistical results in the sense of generating higher $t$-statistics. The dichotomised variable became statistically significant when students worked more than 10 to 12 hours per week, a finding that is consistent with the literature.

${ }^{\dagger}$ A range of non-linear variants of the age variable were tested, including quadratic and cubic formulations, but the formulation used here was the only one that proved to consistently statistically significant.
} 
qualification, 0 otherwise) appeared not to have a statistically significant influence on achievement.

Apart from hours spent per week in seminar preparation, all statistically significant coefficients are of the expected sign (assuming that it might be expected that those students with BTEC vocational qualifications will, if anything, exhibit relatively poor performance, although this variable is significant at the $10 \%$ level only). The hours spent per week in seminar preparation has an unexpected negative sign - the more hours spent per week in seminar preparation the worse is assessment performance. If students who undertake more than 9 hours seminar preparation per week are excluded (a total of 11 students) the impact of this variable is no longer statistically significant, although the variable never reverts to positive significance if students continue to be excluded on the basis of a reducing level of the hours spent per week in seminar preparation. Indeed, the average level of hours spent per week in seminar preparation for fail students was 4.6 hours compared to 2.9 hours for pass students, a difference that is statistically significant at the one per cent level. By contrast the log of the total hours spent in completing the assessment has a positive impact on performance, as expected - pass students spent an average of 42.8 hours completing the assessment compared to an average of 31.0 hours for fail students, a difference that is significant at the five per cent level. This issue will be considered further in the following section. 
Equation (2) includes the average grade across all modules, excluding QM101 $(A V G R A D E)$. As might be expected the variable is highly statistically significant, with the paid employment variable now no longer appearing as significant. The statistical significance of the other influences identified in Equation (1) remains - that is, the hours spent per week in seminar preparation, the log of the total hours spent in completing the assessment, whether or not students enter on the basis of BTEC NC/ND qualifications, gender, and the mix of age variables.

Table 5 also presents three diagnostic tests - a test for functional form (Ramsey's RESET test), a test for normality of residuals (Bera-Jarque test), and Koenker's test for heteroscedasticity. ${ }^{*}$ The associated test statistics are in all cases not statistically significant.

Given the gender and age effects in Equations (1) and (2), it would seem appropriate to estimate separate regressions for males and females, and mature students (aged 21 or over) and standard-age students. These are shown in Table 6 (for gender) and Table 7 (mature/standard-age), again for regressions including and excluding AVGRADE.

[Insert Table 6 about here]

From Table 6 the total hours spent in completing the assessment is consistently statistically significant, with the hours spent per week in seminar preparation continuing to

\footnotetext{
* The regression package used to generate these statistics is Microfit 4.1. See Pesaran and Pesaran [43] for a description of these tests.
} 
have a negative impact on performance, apart from the case of Equation (6). Commitment to paid employment is significant only for males. In the case of males there is evidence that the possession of matriculation qualifications has a positive impact on performance (Equation (5)), but this influence drops out once the $A V G R A D E$ variable is included. In the case of females those admitted on the basis of BTEC NC/ND qualifications perform relatively poorly. The effect of age is the same as in the aggregate equations in Table 5.

Table 7 presents the regressions for mature and standard-age students. In the case of mature students the hours spent per week in seminar preparation, the log of the total hours spent in completing the assessment and commitment to paid employment all have a statistically significant impact on performance. The number of IT seminars attended appears to be relevant in the case of mature students (ITSEMINARS), and those with BTEC NC/ND qualifications performed relatively poorly. The age effect is similar to that in Tables 5 and 6 . In the case of standard-age students (Equations (9) and (10)), the only consistent influences on performance are the log of the hours spent in completing the assessment and $A V G R A D E$, with a weak influence coming from the hours spent per week in paid employment (but this time if weekly hours of work exceed 10 hours - WORK10, and for Equation (9) only), and some evidence of a gender effect (standard-age females outperform standard-age males Equation (10)) - the regressions for standard-age students imply a relatively unpredictable environment.

[Insert Table 7 about here] 
In most cases reasonable $R^{2} \mathrm{~s}$ are produced, given the cross-section nature of the analysis, and relatively large sample sizes. However, no claim is being made here that all the systematic influences on student performance have been captured. In addition it might also be argued that student performance is inherently 'noisy', and subject to a range of unobservable and unquantifiable influences. This would appear to be particularly the case for standard-age students. Therefore the conclusions drawn here are best interpreted as partial in this sense.

\section{Interpretations and Conclusions}

The regression analyses presented in the previous section are necessarily limited in the sense that they cannot provide a basis for deriving a definitive statement of all the factors that influence student performance on the module. Success and achievement will be subject to a range of influences including ability, motivation, learning skills and environmental factors, all of which have only been imperfectly captured here. However, the analysis does raise a number of questions and issues that relate to a HE policy that seeks to widen participation whilst simultaneously reducing inputs per student.

\footnotetext{
* Probit regressions were also run in which the dependent variable simply reflected the pass/fail outcome - that is, the dependent variable took the value 1 if the student achieved $40 \%$ or more on the assessment, 0 otherwise. The results were broadly consistent with the regressions in Tables 5 to 7 , although there were some differences. No gender effects were identified, and age effects were restricted to just males and mature students. Thus, while age and gender appear to have an impact on grade achieved, they have a very limited impact on the probability of passing the module. In general, hours spent on seminar and assessment preparation had a much more limited impact on the probability of passing, as compared to the results in Tables 5 to 7.
} 
It is encouraging to note the relatively weak influence of matriculation qualifications on performance. Students entering with a diverse range of backgrounds can be successful in their performance on the module. Given the studies that demonstrate the poor relationship between entry qualifications and degree performance this weak influence is not surprising. For example, Smith and Naylor [39], while concluding that degree performance is positively related to the strength of entry qualifications (the number of A-level points has a positive impact on degree classification), do not detect any significant differences as between different types of entry qualifications. However, from our analysis here there is some evidence to suggest that entry on the basis of a BTEC NC/ND qualification - a wellestablished vocational qualification within the UK context - has a negative impact on performance. But perhaps not too much should be read into this result. There were only 18 students in the sample with this qualification, 13 of whom were females, hence explaining the concentration of this impact amongst females. The fact that its impact was significant amongst mature students may reflect the unsuitability of older variants of this qualification as a preparation for HE. Smith and Naylor [3], however, find that the strength of matriculation qualifications can have a statistically significant impact on the probability of withdrawal from HE - those with higher A-level points are less likely to withdraw - and similar effects were found for other forms of entry qualifications. So the findings here should perhaps be qualified as being conditional upon continuation in HE.

Given the extent of part-time working undertaken by the cohort (Table 4) it is not surprising that this has a negative impact on performance. From the regressions it would seem that this negative impact sets in beyond about 12 hours employment per week. This is consistent with the findings of Johnston [36], and recommendations by the National Audit 
Office [38]. However, as some $43 \%$ of the full-time cohort worked more than 12 hours per week its impact here is an extensive one.

The disaggregated regressions (Tables 6 and 7) suggest some differences in the impact of paid employment on performance. The disaggregated gender regressions (Table 6) suggest that paid employment impacts negatively on the performance of males, but has no effect in the case of females, even though the extent of paid employment was comparable between the genders (see Table 4). In the absence of further data regarding the nature of the work and working patterns it is not clear why this might be the case. It may also be the case that the impact of part-time working is more subtle than is allowed for here, and may impact differentially across different modules, and may impact more significantly on progression and degree classifications. This remains a focus for further research. Interestingly, Smith and Naylor [3] find a similar gender effect - males from poorer backgrounds are more likely to drop out of university, whereas no such effect was found for females.

Paid employment appeared to have a more marked impact on the performance of mature students as compared to standard-age students (Table 7). No doubt this results, in part, from the more extensive work commitments of mature students $-46 \%$ of mature students work more than 12 hours per week, compared to $37 \%$ of standard-age students (see also Table 4). However the relatively low explanatory power of the standard-age regressions makes it difficult to isolate the impact of paid employment with any precision, and so perhaps not too much should be read into this apparent difference. 
A consistent feature of the analyses is that the extent of engagement with the module, as reflected in the level of effort that is put into the assessment, impacts positively on performance. In addition, and in the case of mature students, the level of attendance at IT seminars also had a positive impact on performance, a result that is perhaps not surprising, given that the use of IT can tend to be a source of insecurity for mature students.

However, the extent to which students engage in the weekly preparation of seminar exercises (irrespective of whether they attend seminars) appears to have a negative impact on performance. While it is the case that this significant negative effect appears to be the result of a number of outlying observations, the fact that the extent of seminar preparation nowhere appears as having a statistically significant and positive impact, in any truncated sample is, superficially at least, anomalous. It may be the case that students tended to exaggerate the extent to which they undertook seminar preparation, the extent of exaggeration being greater amongst the weaker students. However if this were the case then a similar pattern of exaggeration would be expected in the claims made for the extent of assessment preparation undertaken. This does not appear to have occurred given the consistent and positive influence of assessment preparation on performance.

We can only speculate here as to how this anomaly might be explained. A potential explanation may derive from the conflict between the demands placed on students to develop as independent learners and their ability and preparedness to do so. Many students commented negatively upon the perceived effectiveness of the large lecture sessions. If it is the case that in having difficulty understanding lecture content students avoid seminars and are reluctant to seek help, then it is perhaps not surprising that spending a significant amount 
of time trying to work independently through the seminar exercises is not an effective learning strategy. While supplementary maths workshops are provided on a University-wide basis, the nature of this type of support for students assumes a level of self-assessment and the self-confidence and willingness to seek out help that is perhaps unrealistic. This issue was explored in further detail via the inclusion of interaction variables in the regressions in Tables 5 to 7 (results not shown here). Specifically, variables were constructed reflecting the interaction between the time spent on seminar preparation and seminar attendance (SEMPREP* ITSEMINARS and SEMPREP* QMSEMINARS, where QMSEMINARS is the number of QM seminars attended). These variables appeared with statistically significant and positive coefficients in a number of the regressions, but this significance was not robust in the presence of the $A V G R A D E$ variable. However the one exception was in the case of males (Equations (5) and (6) in Table 6). The interaction between seminar preparation and attendance at IT seminars was positive and statistically significant, even after the inclusion of the $A V G R A D E$ variable, with the coefficients on the individual variables (SEMPREP and ITSEMINARS) being negative and significant. Thus this would suggest that it is the combination of preparing seminar work and supervision in seminars that has a beneficial impact, further implying that independent working has limited returns as a learning strategy.

The broadened focus of the national widening participation strategy does appear to be relevant here, particularly to teaching and learning within access institutions. Macdonald and Stratta [6] have pointed to the potential gap between the policy and practice of widening participation and suggest that staff may be ambivalent about identifying and then making specific responses to particular sub-groups of students. With the decline in the mature student population the nature of the student body is changing significantly. There has been an increase in the younger cohort, which is more likely to have undertaken vocational 
programmes or to have entered with matriculation qualifications. Whilst it would be assumed that those with matriculation qualifications would be better able to cope with the demands of $\mathrm{HE}$, the effect is perhaps marginal, as is suggested by our regression analysis. For an inner city institution specifically targeting a diverse student intake it is likely that the issues of poor achievement in mathematics and low levels of confidence and motivation will be a relevant factor for a significant number of students.

The module has been designed to assume limited prior achievement in mathematics. However within the general context of HE, assumptions are made about student motivation to learn and the ability to engage in a certain level of independence in learning (Cook and Leckey [40]). It may be the case that mature students are better able to engage with this style of delivery, and this may be due, as the literature suggests, to a difference in their learning style and a propensity to engage with learning on the basis of a desire to understand the material rather than simply pass the module. The returns to maturity identified in our analysis are consistent with such an interpretation. This issue is also referred to in the National Audit Office report [38], which notes concerns by HE institutions that '16-18 education is increasingly becoming a continuation of pre-16 education.'.. and that 'in the current environment of school and college league tables, students tend to be "spoon-fed" for longer, and are now less well-equipped with individual or self-learning skills.' Fazey and Fazey [41] also point to the inappropriateness of assuming sophisticated autonomous learning skills on the part of new entrants into HE. This point seems to us to be an important factor when considering appropriate learning and teaching strategies within a widening participation context, particularly with respect to mathematics/statistics. The significance of the prior learning experience of students will be important not primarily as an indicator of the level of 
prior achievement but in respect of individual student motivation, confidence and preparedness for the level of independence traditionally demanded of study in HE.

It is undoubtedly difficult to focus upon the development of the individual within a mass HE system. While the analysis presented here relates to just one specific module, and hence limited claims can be made about the generality of our conclusions, our initial analysis does appear to lend support to suggestions made in the literature that it will be important to structure the learning environment to develop independence and nurture individual potential. This in turn implies that significant benefits may accrue from a resourcing model which facilitates the use of small group sessions to promote the learning development of individuals, with the focus upon supported learning taking place in the seminar with limited expectations of independent working at this stage of the course. Such an approach would be consistent with the literature review which suggested that students' lack of confidence with numeracy should not be seen as an individual personality characteristic but as socially constructed, and which needs to be addressed within a widening participation strategy. Inherent in such an approach is perhaps a broader challenge to universities engaging in widening participation. The issues are complex and student development will require time and planning across the whole curriculum. The literature would suggest such cultural changes have yet to be implemented in many cases. Universities persist in learning and teaching patterns and resourcing which have been traditional in HE. There is also here perhaps a challenge to the short termism of modularity - with its rapid summative assessment events that require students to be up to speed within weeks of enrolling on a course for which they may be illprepared (Longden [4]). There may also be a role for the considered use of learning technologies to support the feedback and assessment process. However, there is a danger that computer-based approaches may be seen to substitute rather than to complement the tutor 
contact required to support student feedback. Computer-based approaches to learning have often been argued to have the potential to both develop independent learning skills and to provide a cost effective approach to the teaching and learning process. However a recent study by Angrist and Lavy [42], although focused on pre-university learning, expresses deep scepticism of such claims. The study was based on a random sample of 200 elementary and middle schools, and included nearly 5,000 pupils. It examined performance in mathematics and languages, with a specific emphasis on the impact that computer-aided instruction had on performance. The study, using highly detailed and sophisticated statistical analyses, concluded that, at best, the impact on performance was not statistically significant, with some evidence to suggest that the impact may even be negative.

The rapid shift in the widening participation agenda has resulted in many universities being required to engage directly with an increasing proportion of relatively ill-prepared standard-aged students. Even for universities with an access tradition this raises different issues from those raised by their traditional mature student entrants. Clearly in the longer term a genuine and effective widening participation strategy requires a secondary education system that is resourced to support such a strategy. However in the medium term supporting diverse groups of students seems to us to require a focus upon the individual student, with all the resource implications that this has. Without this connection between policy and practice the sector is set to continue to fail the very same students who have experienced it all before. 


\section{References}

[1] Smith, A., 2004, Making Mathematics Count: Report of the Inquiry into Post-14 Mathematics Education Department for Education and Skills Publications.

[2] Hoyles, C., Wolf, A., Molyneux-Hodgson, S. and Kent, P., 2002, Mathematical Skills in the Workplace: Final Report to the Science, Technology and Mathematics Council Institute of Education, University of London.

[3] Smith, J.P. and Naylor, R.A., 2001, 'Dropping out of University: a statistical analysis of the probability of withdrawal for UK university students.' Journal of the Royal Statistical Society, Series A, 164, Part 2, 389-405.

[4] Longden, B., 2002, 'Retention rates - renewed interest but whose interest is being served?' Research Papers in Education, 17 (1), 3-29.

[5] Marks, A., 2001, 'The Unravelling of a sector: does the introduction of fees spell the end of education for all?' Journal of Further and Higher Education, 25, 2, 195-215.

[6] Macdonald C and Stratta E, 2001, 'From Access to Widening Participation: responses to the changing population in Higher Education in the UK' Journal of Further and Higher Education, 25, 2, 195-215.

[7] Burton, L., 1990, Gender and mathematics: an international perspective Cassell.

[8] Dowling, P., 1998, The sociology of mathematics education: mathematical myths/pedagogic texts Falmer Press. 
[9] Walden, R. and Walkerdine, V., 1986, 'Characteristics, Views and Relationships in the Classroom.' in Burton, L.(ed.) Girls into maths can go. Holt.

[10] Gorard, S., Selwyn, N., and Williams, S., 2000, Must try harder! Problems facing technological solutions to non- participation in adult learning.' British Educational Research Journal, 26, 4, 507-521.

[11] Brown, M., Millett, A., Bibby, T.and David, C., 2000, 'Turning our attention from the what to the how: the national numeracy strategy.' British Educational Research Journal, 26, $4,457-471$.

[12] Richardson, J.T.E., 1995, 'Mature students in higher education: II. An investigation of approaches to studying and academic performance', Studies in Higher Education, 20, 1, 5-17.

[13] Dickson, J., Fleet, A. and Watt, H.M.G., 2000, 'Success or Failure in a Core University Unit: what makes the difference?' Higher Education Research and Development, 19, 1, 5973.

[14] McGivney, V., 1996, Staying or Leaving the Course: Non-Completion and Retention of Mature Students in Further and Higher Education National Institute of Adult Continuing Education, Leicester.

[15] Hirst, K., 1999, 'Mature students studying mathematics.' International Journal of Mathematical Education in Science and Technology, 30, 2, 207-213.

[16] Bowl, M., 2001, 'Experiencing the barriers: non-traditional students entering higher education.' Research Papers in Education, 16 (2), 141-160. 
[17] Tett, L., 1999, 'Widening provision in higher education - some non-traditional participants' experiences.' Research Papers in Education, 14 (1), 107-119.

[18] Archer, J., Cantwell, R. and Bourke, S., 1999, 'Coping at university: an examination of achievement, motivation, self-regulation, confidence and method of entry.' Higher Education Research and Development, 18, 1, 31-54.

[19] Tobias, S., 1980, 'Math anxiety: what you can do about it.' Todays Education, 69, 3, 2629.

[20] Hembree, R., 1990, 'The nature effects and relief of maths anxiety,' Journal for Research in Maths Education, 21, 33-46.

[21] Boaler J., William, D. and Brown, M., 2000, 'Students' experiences of ability groupingdisaffection, polarisation and the construction of failure.' British Educational Research Journal, 26, 5, 631-648.

[22] Breen, R. and Lindsay, R., 1999, 'Academic research and student motivation.' Studies in Higher Education, 24, 1, 75-93.

[23] Wilcox, S., 1996, 'Fostering self-directed learning in the university setting.' Studies in Higher Education, 21, 2, 165-176.

[24] Montgomery, D., 1993, 'Fostering learner-managed-learning in teacher education' in Graves, N. (ed.) Learner Managed Learning: Practice, Theory and Policy. World Education Fellowship. 
[25] Grayson, A., Clarke, D.D. and Miller, H., 1998, 'Help-seeking among students: are lecturers seen as a potential source of help?' Studies in Higher Education, 23, 2, 143-155.

[26] Gibbs, G., Lucas, L. and Simonite V., 1996, 'Class size and student performance: 198494.' Studies in Higher Education, 21, 3, 261-273.

[27] Eide, E. and Showalter, M., 1998, 'The effect of school quality on student performance: A quantile regression approach.' Economic Letters, 58, 345-350.

[28] Lindsay, R. and Paton-Saltzberg, R., 1987, 'Resource changes and academic performance at an English polytechnic.' Studies in Higher Education, 12, 213-227.

[29] Mahler, S., Neumann, L. and Tamir, P., 1986, 'The class-size effect upon activity and cognitive dimensions of lessons in higher education,' Assessment and Evaluation in Higher Education, 11, 43-59.

[30] Goldfinch J., 1996, 'The effectiveness of school type classes compared to the traditional lecture tutorial method for teaching quantitative methods to business students.' Studies in Higher Education, 21, 2, 207-220.

[31] Hubbard, R., 1991, 53 Interesting Ways to Teach Mathematics (Bristol, Bristol Technical and Educational Services Ltd).

[32] Isaacs, G., 1994, 'Lecture practices and note-taking purposes.' Studies in Higher Education, 19, 2, 203-216.

[33] Ford, J., Bosworth, D. and Wilson, R., 1995, 'Part-time work and full-time higher education' Studies in Higher Education, 20, 2, 187-202. 
[34] Sorensen, L and Winn, S., 1993, 'Student loans a case study.' Higher Education Review, $25,48-65$.

[35] Paton-Saltzberg, R. and Lindsay, R., 1993, 'The effects of paid employment on the academic performance of full-time students in higher education.' Oxford, Oxford Brookes University.

[36] Johnston, V., 2001, Evidence for the Education \& Employment Committee: Inquiry into Higher Education: Student Retention Napier University, Edinburgh

[37] Christie, H., Munro, M. and Rettig, H., 2001, 'Making Ends Meet: student incomes and debt.' Studies in Higher Education, 26, 3, 363-383.

[38] National Audit Office, 2002, Improving student achievement in English Higher Education NAO, London.

[39] Smith, J.P. and Naylor, R.A., 2001, 'Determinants of degree performance in UK universities: a statistical analysis of the 1993 student cohort.' Oxford Bulletin of Economics and Statistics, 63, 1, 29-60.

[40] Cook, A and Leckey, J., 1999, 'Do expectations meet reality? A survey of changes in first year student opinion', Journal of Further and Higher Education, 23, 157-171.

[41] Fazey, D.M.A and Fazey, J.A., 2001, 'The Potential for Autonomy in Learning: perceptions of competence, motivation and locus of control in first year undergraduate students.' Studies in Higher Education, 26, 3, 345-361. 
[42] Angrist, J and Lavy, V., 2002, 'New Evidence on Classroom Computers and Pupil Learning.' Economic Journal, 112, 735-765.

[43] Pesaran, M.H and Pesaran, B., 1997, Working with Microfit 4.0 Oxford University Press, Oxford. 
Table 1

Age and Gender Breakdown of Student Cohort, 2000/1 and 1997/8

\begin{tabular}{|c|c|c|c|c|}
\hline Age Group & $\begin{array}{c}\text { Females } 2000 / 1 \\
\text { Number }(\%)\end{array}$ & $\begin{array}{l}\text { Males 2000/1 } \\
\text { Number (\%) }\end{array}$ & $\begin{array}{c}\text { Females } 1997 / 8 \\
\text { Number }(\%)\end{array}$ & $\begin{array}{l}\text { Males1997/8 } \\
\text { Number (\%) }\end{array}$ \\
\hline 20 or Below & $138(64.5)$ & $68(60.7)$ & $145 \quad(48.8)$ & $88 \quad(40.6)$ \\
\hline $21-24$ & $51 \quad(23.8)$ & $18 \quad(16.1)$ & $74 \quad(24.9)$ & 69 (31.6) \\
\hline $25-35$ & $24 \quad(11.2)$ & 20 (17.9) & $69 \quad(23.2)$ & 51 (23.3) \\
\hline 35 and Over & $1 \quad(0.5)$ & $3 \quad(2.7)$ & $9 \quad(3.0)$ & $10 \quad(4.5)$ \\
\hline Not Known & - & $3 \quad(2.7)$ & & \\
\hline Total & $214(100.0)$ & $112(100.0)$ & $297(100.0)$ & $218(100.0)$ \\
\hline
\end{tabular}


Table 2

Ethnic Breakdown of Student Cohort

\begin{tabular}{|l|cc|}
\hline Ethnicity & Frequency & $\%$ \\
\hline Bangladeshi/Indian/Pakistani & 51 & 15.6 \\
Black African/Caribbean/Other & 67 & 20.6 \\
White & 132 & 40.5 \\
Other & 53 & 16.3 \\
Not Known & 23 & 7.1 \\
\hline Total & 326 & 100.0 \\
\hline
\end{tabular}


Table 3

Student Cohort by Qualifications on Entry

\begin{tabular}{|l|rrrr|}
\hline Qualifications on Entry & \multicolumn{2}{|c}{$2000 / 1$} & \multicolumn{2}{c|}{$1997 / 8$} \\
& \multicolumn{2}{|c|}{ Number (\%) } & \multicolumn{2}{c|}{ Number (\%) } \\
\hline Matriculation Qualifications & 103 & $(31.6)$ & 174 & $(33.8)$ \\
Vocational Qualifications & 107 & $(32.8)$ & 85 & $(16.6)$ \\
Access/Foundation Course & 21 & $(6.4)$ & 69 & $(13.5)$ \\
HE/Prof Qualifications & 25 & $(7.7)$ & 35 & $(6.8)$ \\
None- Mature Student & 13 & $(4.0)$ & 38 & $(7.3)$ \\
Other (Overseas) & 52 & $(16.0)$ & 112 & $(21.7)$ \\
Not Known & 5 & $(1.5)$ & 2 & $(0.3)$ \\
\hline Total & 326 & $(100.0)$ & 515 & $(100.0)$ \\
\hline
\end{tabular}


Table 4

Summary Statistics relating to Weekly Hours of Paid Employment

\begin{tabular}{|l|cccc|}
\hline & $\begin{array}{c}\text { Percentage in } \\
\text { Employment }\end{array}$ & $\begin{array}{c}\text { Average } \\
\text { Weekly Hours }\end{array}$ & $\begin{array}{c}\text { Median } \\
\text { Weekly Hours }\end{array}$ & $\begin{array}{c}\text { Standard } \\
\text { Deviation }\end{array}$ \\
\hline Males & 55.7 & 18.0 & 18.0 & 7.3 \\
Females & 58.9 & 16.1 & 16.0 & 6.0 \\
Mature & 65.1 & 18.6 & 20.0 & 6.1 \\
Standard-Age & 54.8 & 15.5 & 15.0 & 6.3 \\
\hline Total & 57.8 & 16.7 & 16.0 & 6.5 \\
\hline
\end{tabular}


Table 5

Regressions for Assessment Grade, All Students

\begin{tabular}{|c|c|c|}
\hline $\begin{array}{l}\text { Independent } \\
\text { Variables }\end{array}$ & $\begin{array}{c}\text { Equation (1) } \\
\text { Coefficient } \\
\text { (t-statistic) }\end{array}$ & $\begin{array}{c}\text { Equation (2) } \\
\text { Coefficient } \\
(t \text {-statistic) }\end{array}$ \\
\hline CONSTANT & $\begin{array}{c}158.491^{* * *} \\
(4.05)\end{array}$ & $\begin{array}{c}105.249^{* * *} \\
(2.86)\end{array}$ \\
\hline SEMPREP & $\begin{array}{l}-0.892^{* * *} \\
(-3.05)\end{array}$ & $\begin{array}{l}-0.648^{* *} \\
(-2.40)\end{array}$ \\
\hline $\ln (A S S P R E P)$ & $\begin{array}{l}3.990^{* * *} \\
(3.44)\end{array}$ & $\begin{array}{l}2.678^{* *} \\
(2.47)\end{array}$ \\
\hline WORK 12 & $\begin{array}{l}-3.273^{* *} \\
(-2.00)\end{array}$ & $\begin{array}{c}-2.379 \\
(-1.57)\end{array}$ \\
\hline ITSEMINARS & $\begin{array}{r}0.291 \\
(0.65)\end{array}$ & $\begin{array}{r}0.018 \\
(0.04)\end{array}$ \\
\hline$A V G R A D E$ & & $\begin{array}{l}0.541^{* * *} \\
(6.58)\end{array}$ \\
\hline MATRIC & $\begin{array}{r}2.674 \\
(1.49)\end{array}$ & $\begin{array}{r}0.332 \\
(0.20)\end{array}$ \\
\hline$B T E C N C / N D$ & $\begin{array}{l}-6.067^{*} \\
(-1.70)\end{array}$ & $\begin{array}{l}-6.358^{*} \\
(-1.95)\end{array}$ \\
\hline GENDER & $\begin{array}{l}2.921^{*} \\
(1.67)\end{array}$ & $\begin{array}{l}3.382^{* *} \\
(2.10)\end{array}$ \\
\hline $\operatorname{Ln}(A G E)$ & $\begin{array}{l}-42.067^{* * *} \\
(-3.20)\end{array}$ & $\begin{array}{l}-31.148^{* *} \\
(-2.56)\end{array}$ \\
\hline$A G E 21$ & $\begin{array}{l}12.192^{* * *} \\
(3.65)\end{array}$ & $\begin{array}{l}8.096^{* * *} \\
(2.59)\end{array}$ \\
\hline$A G E 30$ & $\begin{array}{l}20.896^{* * *} \\
(3.59)\end{array}$ & $\begin{array}{l}19.382^{* * *} \\
(3.62)\end{array}$ \\
\hline$R^{2}$ & 0.212 & 0.340 \\
\hline$n$ & 236 & 236 \\
\hline Functional Form $\left[\chi^{2}(1)\right]$ & 0.462 & 0.277 \\
\hline Normality $\left[\chi^{2}(2)\right]$ & 0.340 & 0.742 \\
\hline Heteroscedasticity $\left[\chi^{2}(1)\right]$ & 0.358 & 0.523 \\
\hline
\end{tabular}


Table 6

Regressions for Assessment Grade by Gender

\begin{tabular}{|c|c|c|c|c|}
\hline $\begin{array}{l}\text { Independent } \\
\text { Variables }\end{array}$ & $\begin{array}{c}\text { Equation (3) } \\
\text { Females } \\
\text { Coefficient } \\
(t \text {-statistic) }\end{array}$ & $\begin{array}{c}\text { Equation (4) } \\
\text { Females } \\
\text { Coefficient } \\
(t \text {-statistic) }\end{array}$ & $\begin{array}{c}\text { Equation (5) } \\
\text { Males } \\
\text { Coefficient } \\
(t \text {-statistic) }\end{array}$ & $\begin{array}{c}\text { Equation (6) } \\
\text { Males } \\
\text { Coefficient } \\
\text { ( } t \text {-statistic) }\end{array}$ \\
\hline CONSTANT & $\begin{array}{c}146.327^{* * *} \\
(2.79)\end{array}$ & $\begin{array}{c}107.544^{* *} \\
(2.08)\end{array}$ & $\begin{array}{c}164.681^{* * *} \\
(2.72)\end{array}$ & $\begin{array}{c}100.673^{* *} \\
(2.01)\end{array}$ \\
\hline SEMPREP & $\begin{array}{l}-0.894^{* * *} \\
(-2.76)\end{array}$ & $\begin{array}{l}-0.707^{* *} \\
(-2.24)\end{array}$ & $\begin{array}{l}-1.318^{*} \\
(-1.70)\end{array}$ & $\begin{array}{l}-0.933 \\
(-1.48)\end{array}$ \\
\hline $\ln (A S S P R E P)$ & $\begin{array}{l}4.211^{* * *} \\
(3.03)\end{array}$ & $\begin{array}{l}2.860^{* *} \\
(2.06)\end{array}$ & $\begin{array}{c}4.272^{*} \\
(1.91)\end{array}$ & $\begin{array}{l}3.964^{* *} \\
(2.18)\end{array}$ \\
\hline WORK 12 & $\begin{array}{l}-2.041 \\
(-1.00)\end{array}$ & $\begin{array}{l}-1.651 \\
(-0.84)\end{array}$ & $\begin{array}{l}-6.037^{* *} \\
(-2.05)\end{array}$ & $\begin{array}{l}-4.073^{*} \\
(-1.69)\end{array}$ \\
\hline ITSEMINARS & $\begin{array}{c}0.438 \\
(0.74)\end{array}$ & $\begin{array}{c}0.258 \\
(0.45)\end{array}$ & $\begin{array}{c}0.112 \\
(0.15)\end{array}$ & $\begin{array}{c}-0.322 \\
(-0.52)\end{array}$ \\
\hline$A V G R A D E$ & & $\begin{array}{l}0.403^{* * *} \\
(3.55)\end{array}$ & & $\begin{array}{l}0.718^{* * *} \\
(6.15)\end{array}$ \\
\hline MATRIC & $\begin{array}{c}0.323 \\
(0.14)\end{array}$ & $\begin{array}{c}-0.994 \\
(-0.45)\end{array}$ & $\begin{array}{l}7.101^{* *} \\
(2.39)\end{array}$ & $\begin{array}{r}2.760 \\
(1.10)\end{array}$ \\
\hline$B T E C N C / N D$ & $\begin{array}{l}-10.311^{* *} \\
(-2.27)\end{array}$ & $\begin{array}{l}-9.518^{* *} \\
(-2.17)\end{array}$ & $\begin{array}{r}0.315 \\
(0.05)\end{array}$ & $\begin{array}{l}-3.183 \\
(-0.63)\end{array}$ \\
\hline $\ln (A G E)$ & $\begin{array}{l}-37.516^{* *} \\
(-2.13)\end{array}$ & $\begin{array}{c}-29.180^{*} \\
(-1.71)\end{array}$ & $\begin{array}{l}-43.867^{* *} \\
(-2.12)\end{array}$ & $\begin{array}{c}-33.069^{*} \\
(-1.96)\end{array}$ \\
\hline$A G E 21$ & $\begin{array}{l}11.294^{\text {*** }} \\
(2.68)\end{array}$ & $\begin{array}{c}7.946^{*} \\
(1.91)\end{array}$ & $\begin{array}{l}12.793^{* *} \\
(2.16)\end{array}$ & $\begin{array}{c}9.193^{*} \\
(1.90)\end{array}$ \\
\hline$A G E 30$ & $\begin{array}{l}19.616^{* *} \\
(2.51)\end{array}$ & $\begin{array}{l}18.117^{* *} \\
(2.41)\end{array}$ & $\begin{array}{l}22.820^{* *} \\
(2.28)\end{array}$ & $\begin{array}{l}20.179^{* * *} \\
(2.73)\end{array}$ \\
\hline$R^{2}$ & 0.191 & 0.256 & 0.265 & 0.523 \\
\hline$n$ & 155 & 155 & 81 & 81 \\
\hline Functional Form $\left[\chi^{2}(1)\right]$ & 0.680 & 0.311 & 0.002 & 0.278 \\
\hline Normality $\left[\chi^{2}(2)\right]$ & 2.302 & 1.276 & 1.942 & 0.015 \\
\hline Heteroscedasticity $\left[\chi^{2}(1)\right]$ & 0.388 & 1.037 & 0.071 & 1.368 \\
\hline
\end{tabular}


Table 7

Regressions for Assessment Grade by Age Group

\begin{tabular}{|c|c|c|c|c|}
\hline $\begin{array}{l}\text { Independent } \\
\text { Variables }\end{array}$ & $\begin{array}{c}\text { Equation (7) } \\
\text { Mature } \\
\text { Coefficient } \\
(t \text {-statistic) }\end{array}$ & $\begin{array}{l}\text { Equation (8) } \\
\text { Mature } \\
\text { Coefficient } \\
\text { ( } t \text {-statistic) }\end{array}$ & $\begin{array}{c}\text { Equation (9) } \\
\text { Standard-Age } \\
\text { Coefficient } \\
(t \text {-statistic) }\end{array}$ & $\begin{array}{c}\text { Equation (10) } \\
\text { Standard-Age } \\
\text { Coefficient } \\
(t \text {-statistic) }\end{array}$ \\
\hline CONSTANT & $\begin{array}{c}156.959^{* * *} \\
(3.15)\end{array}$ & $\begin{array}{c}101.766^{* *} \\
(2.15)\end{array}$ & $\begin{array}{c}144.561^{* *} \\
(2.04)\end{array}$ & $\begin{array}{c}107.252 \\
(1.62)\end{array}$ \\
\hline SEMPREP & $\begin{array}{l}-1.264^{* * *} \\
(-3.02)\end{array}$ & $\begin{array}{l}-0.946^{* *} \\
(-2.43)\end{array}$ & $\begin{array}{l}-0.551 \\
(-1.36)\end{array}$ & $\begin{array}{c}-0.400 \\
(-1.06)\end{array}$ \\
\hline $\ln (A S S P R E P)$ & $\begin{array}{l}5.271^{* * *} \\
(2.85)\end{array}$ & $\begin{array}{r}2.873 \\
(1.61)\end{array}$ & $\begin{array}{l}3.457^{* *} \\
(2.31)\end{array}$ & $\begin{array}{l}2.816^{* *} \\
(2.01)\end{array}$ \\
\hline WORK12 & $\begin{array}{l}-6.545^{* *} \\
(-2.44)\end{array}$ & $\begin{array}{l}-6.177^{* *} \\
(-2.52)\end{array}$ & & \\
\hline WORK10 & & & $\begin{array}{l}-3.503^{*} \\
(-1.70)\end{array}$ & $\begin{array}{l}-1.764 \\
(-0.90)\end{array}$ \\
\hline ITSEMINARS & $\begin{array}{l}1.654^{* *} \\
(2.35)\end{array}$ & $\begin{array}{l}1.412^{* *} \\
(2.19)\end{array}$ & $\begin{array}{c}-0.398 \\
(-0.67)\end{array}$ & $\begin{array}{l}-0.635 \\
(-1.15)\end{array}$ \\
\hline$A V G R A D E$ & & $\begin{array}{l}0.505^{* * *} \\
(4.06)\end{array}$ & & $\begin{array}{l}0.546^{* * *} \\
(4.84)\end{array}$ \\
\hline MATRIC & $\begin{array}{c}4.784 \\
(1.47)\end{array}$ & $\begin{array}{c}2.484 \\
(0.82)\end{array}$ & $\begin{array}{r}2.348 \\
(1.09)\end{array}$ & $\begin{array}{l}-0.083 \\
(0.04)\end{array}$ \\
\hline$B T E C N C / N D$ & $\begin{array}{l}-10.422^{* *} \\
(-1.99)\end{array}$ & $\begin{array}{l}-8.406^{*} \\
(-1.75)\end{array}$ & $\begin{array}{l}-4.210 \\
(-0.85)\end{array}$ & $\begin{array}{r}-5.647 \\
(-1.23)\end{array}$ \\
\hline GENDER & $\begin{array}{r}2.315 \\
(0.79)\end{array}$ & $\begin{array}{r}2.239 \\
(0.84)\end{array}$ & $\begin{array}{c}2.572 \\
(1.18)\end{array}$ & $\begin{array}{c}3.380^{*} \\
(1.67)\end{array}$ \\
\hline $\ln (A G E)$ & $\begin{array}{l}-42.085^{* * *} \\
(-2.73)\end{array}$ & $\begin{array}{l}-30.028^{* *} \\
(-2.09)\end{array}$ & $\begin{array}{c}-34.654 \\
(-1.45)\end{array}$ & $\begin{array}{c}-30.224 \\
(-1.36)\end{array}$ \\
\hline$A G E 30$ & $\begin{array}{l}20.948^{* * *} \\
(3.29)\end{array}$ & $\begin{array}{l}18.387^{* * *} \\
(3.16)\end{array}$ & & \\
\hline$R^{2}$ & 0.421 & 0.526 & 0.117 & 0.243 \\
\hline$n$ & 85 & 85 & 151 & 151 \\
\hline Functional Form $\left[\chi^{2}(1)\right]$ & 0.721 & 0.281 & $3.546^{*}$ & 2.680 \\
\hline Normality $\left[\chi^{2}(2)\right]$ & 0.396 & 1.365 & 0.956 & 0.924 \\
\hline Heteroscedasticity $\left[\chi^{2}(1)\right]$ & 0.546 & 0.583 & 0.949 & 2.330 \\
\hline
\end{tabular}

${ }^{* * *}$ Significant at the $1 \%$ level, ${ }^{* *}$ Significant at the $5 \%$ level, ${ }^{*}$ Significant at the $10 \%$ level 